Landslides (2021) 18:3-4

DOI 10.1007/s10346-020-01577-2

Received: 17 November 2020

Accepted: 17 November 2020

Published online: 20 January 2021

(c) Springer-Verlag GmbH Germany

part of Springer Nature 2021

\section{Nicola Casagli \\ Foreword by Nicola Casagli}

The year 2020 marks a significant milestone for the International Consortium on Landslides (ICL), and in general for landslide community worldwide as in 5 November 2020, we have celebrated the launch of the Kyoto 2020 Landslide Commitment (KLC2020). The KLC2020 supports the implementation, follow-up, and review of the Sendai Framework, the 2030 UN Agenda for Sustainable Development, the New Urban Agenda and the Paris Climate Agreement as it addresses the adverse effects of climate change (Sassa, 2019a; Sassa 2019b; Sassa, 2020a).

The KLC2020 exploits the activities promoted by the Sendai Landslide Partnerships 2015-2025 for Global Promotion of Understanding and Reducing Landslide Disaster Risk that was proposed by the International Consortium on Landslides (ICL) during the 3rd World Conference on Disaster Risk Reduction (WCDRR) in Sendai, Japan in 2015, and was signed by the United Nations and global and national stakeholders.

Up today, the KLC2020 has been signed by about 90 institutions among governmental and international organizations, ICL supporting organizations, ICL full members, ICL associate members, and ICL supporters from 23 countries in 3 continents. All $\mathrm{KLC}_{2} \mathrm{O} 2 \mathrm{O}$ partners are organizations who strongly contribute to understand and reduce landslide disaster risk and who will share their expertise and knowledge in order to build a common platform for sharing ideas, good practices, and policies with key actors and stakeholders concerned with landslide risk at the global level. I acknowledge the great success of KLC2O20 initiative, and I wish to thank all the signatory organizations for their support and commitment.

The KLC2020 proposes 10 priority actions dealing with research and capacity building activities. KLC2020 is planned to continue further to 2030, and it will be examined by the General Conference of KLC2O2O signatory organizations at each World Landslide Forum every 3 years, where priority actions will be updated, and new partners will be invited, thus making the $\mathrm{KLC} 2 \mathrm{O} 2 \mathrm{O}$ as a living and growing and up-to-date initiative. I encourage signatories to pursue the objectives of the $\mathrm{KLC} 2 \mathrm{O} 2 \mathrm{O}$ and to contribute to priority actions.

The year 2020 should have also been the year of the 5th World landslide Forum in Kyoto (WLF5), Japan, 2-6 November. Due to the COVID-19 pandemic, the Organizing Committee of WLF5 has decided to postpone the WLF5 to 2-6 November 2021 at the same venue (Kyoto International Conference Center). Nevertheless, the forum publications have proceeded as scheduled, and they are (i) two thematic issues of Landslides journal which will be published in 2020 and in 2021, the thematic issue "Sendai Landslide Partnerships 20152025 " to be published in October-November 2020 and the thematic issue "Kyoto Landslide Commitment 2020" to be published in October-November 2021; (ii) six volumes of full color books titled "Understanding and Reducing Landslide Disaster Risk," which are the inaugural volumes of new ICL book series "ICL contribution to landslide disaster risk reduction” (ISSN 2662-1894 print version and ISSN2662-1908 electronic version) which will be published in December 2020; and (iii) electronic proceedings to be published in November 2020.

Those individuals that are interested in the upcoming forum can still send their contributions as one-page abstract or e-poster. Further information for submission and deadlines can be found in Sassa (2020b) or at https://wlf5.iplhq.org/call-for-papers/.

I would like also to highlight the great success of the ICL Landslides journal that has reached in 2019 an impact factor of 4.708. The journal has been efficiently managed by its editor-in-chief Kyoji Sassa and assistant editor-in-chief Zeljko Arbanas, with the support from the associate editors: R. Baum, P. Bobrowsky, N. Casagli, J. Corominas, K. Konagai, M. Mikos, C. Ng, L. Picarelli, A. Strom, B. Tiwari, and Y. Yin. Guidance for this work has come from the Editorial Board Advisory Members: S. Briceno, P. Canuti, D. Cruden, E. Derbyshire, W. Eder, I. Ishihara, N. Morgenstern, B. Rouhban, R. Schuster, and T. Takahasi, while a continuous commitment is carried out by the screening editors (K. Sassa, Z. Arbanas, A. Strom, B. Tiwari, V. Tofani, S. Tsuchiya) to make a preliminary evaluation of the manuscripts submitted. On behalf of the International Consortium on Landslides, I express my sincere gratitude to the landslide community for its support in promoting research at world level through significant publications in the journal.

All the above-mentioned achievements reflect the steady and significant increase in relevance and visibility of the consortium within the global community of landslide researchers, practitioners, and stakeholders, and this thanks to the dedication and hard work of the officers and members of the ICL that contribute to the consortium activities initiatives and outputs of the ICL and IPL.

I invite landslide researchers, practitioners, and stakeholders around the world who have benefited from the Landslides journal and from the other ICL and IPL activities, to assist us in the promotion of membership in the ICL. I suggest you examine the full list of membership benefits and details for the various categories: Full Members, ICL Society Members, ICL Supporters, and ICL Associates on our website at the following http:// icl.iplhq.org/ category/icl/registration-and-benefits/.

Finally, I encourage all the actual ICL partner members and potential new ones to continue this effort, to further promote to ICL-IPL activities and Landslides journal. I would like to particularly encourage to pursue KCL2O20 priority actions, and I envisage a strong cooperation among landslide researchers in order to define a common platform for landslide risk reduction on a global scale. 


\section{Preface}

\section{References}

Sassa K (2019a) The fifth world landslide forum and the final draft of the Kyoto 2020 commitment, 16, pp 201-211

Sassa K (2019b) Journal landslides, the international consortium on landslides, and the Kyoto landslide commitment 2020, 16, pp 1623-1628

Sassa K (2020a) Launching session of the Kyoto landslide commitment 2020, 17, pp1743-1744

Sassa K (2020b) The fifth world landslide forum (WLF5) on 2-6 November 2021, Kyoto, Japan, 17, pp. 2005-2011

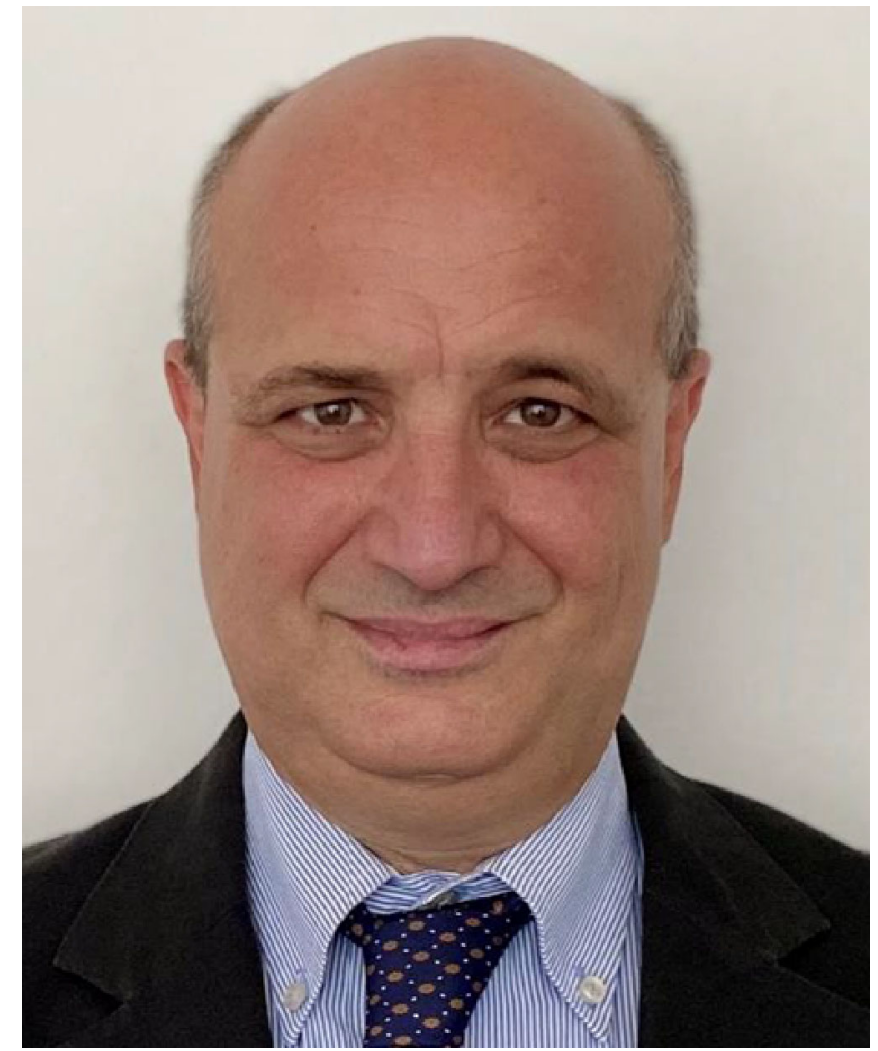

Nicola Casagli

President of the International Consortium on Landslides 